\title{
Prevalence and Risk Factors for Perineal Trauma among Women at a Teaching and Referral Hospital in Kenya
}

\author{
Jacqueline Kituku ${ }^{1 *}$, Amos Getanda $^{2}$, Ann Mwangi ${ }^{3}$ \\ 1 Kenyatta University, School of Nursing, Department of Community and Reproductive Health, P.O. Box 43844- \\ 00100, Kenya \\ 2 Moi University, College of Health sciences, School of Nursing, Department of Midwifery and Gender, P.O. \\ Box 4606-30100, Kenya \\ 3 Moi University, College of Health Sciences, School of Medicine, Department of Behavioural Sciences, P. O. \\ Box 4604-30100, Kenya
}

\begin{abstract}
Perineal trauma is classified according to the degree of structures involved or according to the depth of the injury. Mild perineal trauma is very common following vaginal delivery. Risk factors for perineal trauma include primiparity, precipitate labour, instrumental deliveries, pushing techniques and birth positions. Perineal trauma is associated with significant short-term and long-term complications. The objective of the study was to determine the prevalence and risk factors for perineal trauma among women at teaching and referral hospital in western Kenya. A cross-sectional study was carried out at the teaching hospital between April and May 2015. Two hundred and nine women who had come to deliver at the facility were consented to participate in the study. A structured checklist was used to obtain data from the women and make observations as skilled care givers attended to deliveries. All analyses were performed at 95\% level of confidence. Two hundred and nine (209) deliveries were observed. Majority of the women, $76(36.40 \%)$, were in the $20-24$ age group. Ninety seven (46.10\%) of them were para 0 . Eighty one $(38.8 \%)$ of the women sustained various types of perineal trauma. Supine position during delivery was the most preferred position, in 201 (96.2\%), of the women. Age of the mother, parity, infant birth weight, and history of previous trauma, were statistically significant, associated with trauma in the univariate analysis $(\mathrm{p}=0.013 ; \mathrm{p}=0.000 ; \mathrm{p}=0.010 ; \mathrm{p}=0.033)$ respectively. Adjusting for other factors, the odds of sustaining perineal trauma increased with increased birth weight (OR 2.878; $\mathrm{p}=0.005)$ and decreased with increasing parity (OR $0.037 ; \mathrm{p}=0.000)$. The prevalence of perineal tears as revealed by the study was $38.8 \%$. This study recommended evidence based practice during labour and delivery in order to improve pelvic floor outcomes as well as reduce operative deliveries and long term morbidities.
\end{abstract}

Key words: Perineal trauma, Risk factors, Prevalence, Women

DOI: $10.7176 / \mathrm{JHMN} / 65-09$

Publication date: August $31^{\text {st }} 2019$

\section{Introduction}

Perineal trauma is damage to the genitalia, which occurs during spontaneous child birth or due to a surgical incision or episiotomy (Johanson, 2000). Perineal trauma is broadly classified into $1^{\text {st }}, 2^{\text {nd }}, 3^{\text {rd }}$ and $4^{\text {th }}$ degree tears depending on the perineal structures involved (Gabbe et al., (2007). Another classification considers the depth of injury and involvement of anal sphincter, where mild perineal tears include first and second degree tears, while severe tears are the third and fourth degree perineal tears (Melamed et al., (2013).

In the United Kingdom (UK), occurrence of mild perineal tears is very common among nulliparous women, accounting for $75 \%$, while severe perineal tears are much less common, with prevalence varying between $0.1 \%$ and $8 \%$ (Jackson, 2000). Incidence of $3^{\text {rd }}$ and $4^{\text {th }}$ degree perineal tears have been reported in $0.5 \%$ of vaginal births in the UK, $1.4 \%$ in Japan, 2.5\% in Denmark, 9\% in Canada and 2.9\% in both New Zealand and Australia (Jackson, 2000; Melamed et al., 2013). In a multi-country study carried out by Hirayama et al., (2012), prevalence of $3^{\text {rd }}$ and $4^{\text {th }}$ degree perineal lacerations ranged from $0.1 \%$ to $15.0 \%$. Algeria was leading in the African continent, with a prevalence of $7.2 \%$, followed by Niger with $2.8 \%$, and Kenya coming $4^{\text {th }}$ with $1.1 \%$.

Risk factors of developing $3^{\text {rd }}$ and $4^{\text {th }}$ degree tears include nulliparity, precipitate labor, persistent occipito-posterior position, instrumental delivery particularly forceps as compared to vacuum delivery (Melamed et al., 2013), midline episiotomy, macrosomia, shoulder dystocia, epidural anesthesia and prolonged second stage of labor (Kudish et al., 2008). Some practices such as directed pushing, coached or "closed glottis" Valsalva maneuver may injure maternal pelvic floor structures and also impair bladder function (Lemos et al., 2011). Meyvis et al., (2012) acknowledge that although some risk factors such as nutritional status, maternal body mass index, ethnic origin, birth weight and fetal position, may not be altered during delivery, others such as maternal position may be altered with the possibility of reducing perineal damage.

Whenever they occur, perineal tears are associated with significant short- and long-term morbidity. Significant morbidity is associated with $3^{\text {rd }}$ and $4^{\text {th }}$ degree tears, including the risk of flatus and stool incontinence, rectal 
vaginal fistula, infection, and pain (Gabbe et al, 2007), sexual dysfunction (Komorowski et al., 2014) and risk of recurrence in subsequent pregnancies (Yogev et al., 2014). A study carried out in Australia found that the severity of the perineal trauma increased the incidence of perineal pain at day 1 and 7 (Dahlen \& Homer, 2008). Long term complications of perineal tears may render the mother incapable of attending to family needs and also fending for her family

There is limited data in Kenya on prevalence and risk factors of perineal trauma, as most of the published studies on perineal trauma come from high income countries. It was therefore worthwhile to conduct this study to determine the prevalence and factors associated with perineal trauma among women delivering at a teaching hospital in western Kenya.

\section{Methods}

A descriptive cross-sectional study design was used to carry out this study at Moi teaching and Referral hospital in Uasin Gishu County Kenya in 2014. It entailed observing, describing and documenting the care/management and outcomes of second stage of labour among women. The study was carried out in the labour ward of the teaching hospital in western Kenya. The facility was offering free maternity services at the time of the study, and had recorded 11,415 deliveries in the period July 2013 to June 2014, with an average of 951 deliveries per month (Hospital records 2014). The study population comprised of both the women coming to deliver through spontaneous vertex delivery at teaching facility and the skilled care attendants who performed the deliveries. All women above the age of 18 years coming to the hospital to deliver their babies were selected to participate in this study. All skilled care attendants present and attending to deliveries in the labour ward (midwives, nurses, medical officers, and registrars), were included in the study. Women carrying multiple pregnancies, women considered as having high risk pregnancies, those who had undergone female genital mutilation, medical officer interns, clinical officer interns and students were excluded from the study.

Stratified random sampling was employed to select the women. The women were divided into subsets or strata based on the five delivery rooms such that there were five strata. Simple random sampling was employed in each stratum on a daily basis to select a mother who was to be recruited in to the study, thus one delivery was observed per stratum/delivery room per day to enhance representativeness. This method was most appropriate because deliveries were unpredictable and happened at any time; day or night. A total of two hundred and nine $(n=209)$ women were included in the study. Convenience sampling was employed to select skilled care attendants to participate in the study. Midwives, medical officers and registrars attending to the deliveries of the selected women were all included in the study.

Data was collected through structured observation checklists and interviewer administered questionnaires. Mothers were observed during the second stage of labour. Midwives, nurses, registrars, and medical officers were observed as they conducted deliveries, thus one skilled care giver was observed as they conducted one delivery at a time. A structured questionnaire and observational checklist was completed as per the given instructions. The researcher strictly adhered to research principles and only ticked what was observed in order to reduce observer bias. The Hawthorne effect was also addressed through lengthening the study period (Appendix III), and seeking a waiver of written consent for skilled care attendants from IREC. After delivery the integrity of the perineum was assessed and classified accordingly. The tool was pretested in a public facility that performed deliveries.

Questionnaires and checklists were cleaned, by counter-checking for completeness, errors and inconsistencies. Data was entered into the computer and was analyzed at 95\% level of confidence, using STATA version 13. Descriptive statistics were used to organize and summarize the data. Chi-square was used to test for associations. Multiple logistic regression analysis was used to adjust for confounders. The data was presented in the form of tables, graphs and pie charts. The questionnaires and checklists were stored safely. Data was stored in the computer and a backup was created. Security was ensured by setting up a password.

Permission to carry out the study was sought from the Institutional Research and Ethics Committee (IREC). Permission was also sought from the hospital administration. Written informed consent was sought from the mothers. However, a request for waiver of written consent for the skilled care attendants was sought from IREC. Thus, verbal consent was sought from the skilled care attendants and their rights/welfare was not adversely affected and there was no more than minimum risk. Confidentiality and anonymity was maintained. Respondents were explained of their right to participate in the study voluntarily and to withdraw from it at any time they wished.

\section{Results}

A total of two hundred and nine (209) questionnaires and checklists were analyzed in this study. Majority of the women, 76 (36.40\%), were in the 20-24 age group (Figure 1). Most of the women, 97 (46.10\%) were para 0 and did not have at least one living child. Less than half, $53(46.10 \%)$, of the women who had delivered before had a history of perineal trauma. Among the women who had a history of trauma, $(\mathrm{N}=53)$, perineal tears, $28(52.83 \%)$, 
were the most common as compared to episiotomy, $25(47.17 \%)$. Only $6(16.2 \%)$ had recurrence of trauma in previous deliveries (Table 1).

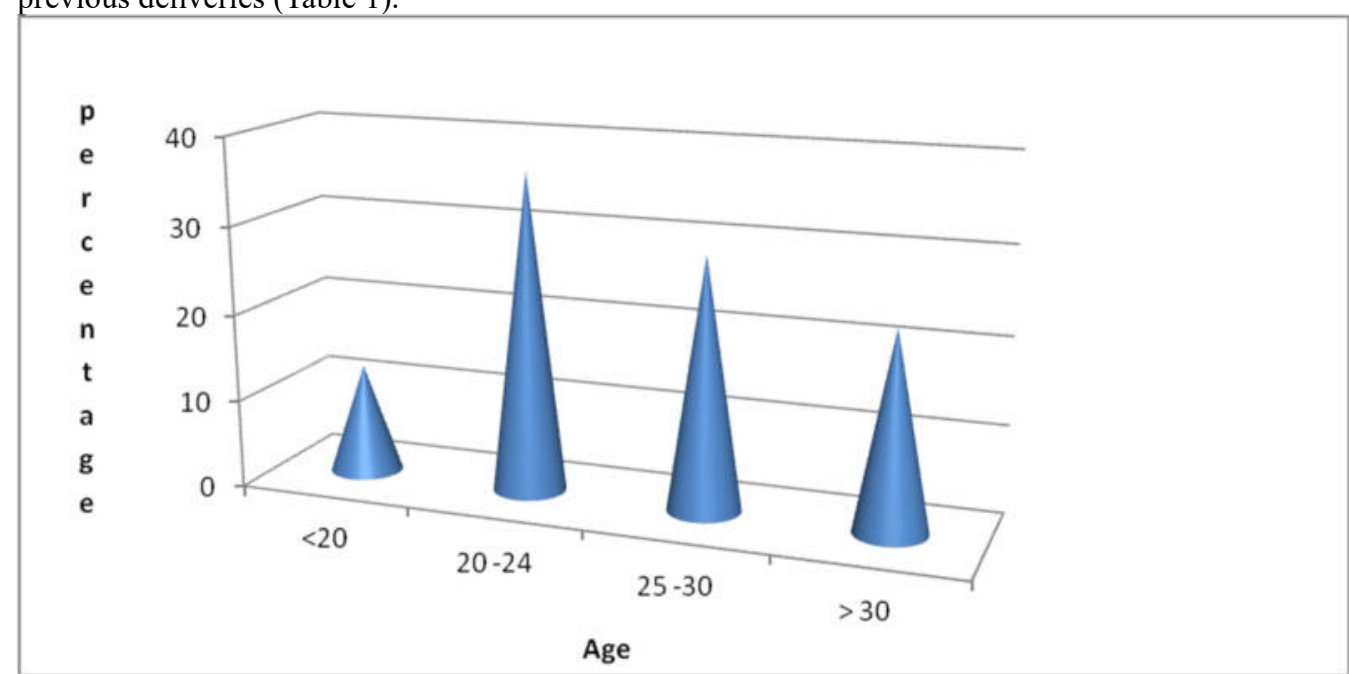

Figure 1: Age of the women $(\mathrm{N}=209)$

Table 1: Demographic characteristics of participating women

\begin{tabular}{lll}
\hline Variable & Freq & $\%$ \\
\hline Parity & $\mathrm{N}=209$ & \\
0 & 97 & $46.10 \%$ \\
1 & 54 & $25.84 \%$ \\
2 & 24 & $11.48 \%$ \\
3 or more & 34 & $16.27 \%$ \\
History of trauma in previous delivery/deliveries) & & \\
No & $\mathrm{N}=115$ & \\
Yes & 62 & $53.90 \%$ \\
Type of trauma in previous delivery/deliveries) & 53 & $46.10 \%$ \\
Episiotomy & $\mathrm{N}=53$ & \\
Tear & 25 & $47.17 \%$ \\
Recurrence of trauma in previous delivery /deliveries) & 28 & $52.83 \%$ \\
No & \multicolumn{2}{|}{} \\
Yes & $\mathrm{N}=37$ & $83.80 \%$ \\
& 31 & $16.20 \%$ \\
\hline
\end{tabular}

Majority of the women, 195 (93.30\%), had spontaneous onset of labour and only the minority $14(6.7 \%)$ had induction of labour. More than three quarters of the deliveries $204(97.6 \%)$, were attended to by nurse/midwives while the remaining $5(2.40 \%)$ were carried out by registrars. In $8(3.80 \%)$ of the deliveries, episiotomy was performed without instrumental delivery (vacuum), while $2(1.00 \%)$ had episiotomy together with vacuum delivery. Majority of the deliveries, $201(96.20 \%)$, were carried out in lithotomy position as compared to $8(3.80 \%)$ in lateral position. The median birth weight was $3.0 \mathrm{kgs}$ with an inter-quartile range of 2.7, 3.4. More than half of the women, $128(61.24 \%)$ had an intact perineum. First degree tears or lacerations were the most common, 60 (28.71\%), type of perineal trauma. Ten $(4.78 \%$ ) of perineal trauma was due to episiotomy (Figure 4.2). During the study period more male babies, $111(53.10 \%)$ were born as compared to the female 98 (46.90\%) (Table 2). 
Table 2: Characteristics of labour and delivery

\begin{tabular}{lll}
\hline Variable & Freq & \% \\
\hline Induction of labour & $\mathbf{N = 2 0 9}$ & \\
No & 195 & $93.30 \%$ \\
Yes & 14 & $6.70 \%$ \\
Skilled care attendant & $\mathbf{N}=\mathbf{2 0 9}$ & \\
Nurse/midwife & 204 & $97.60 \%$ \\
Registrar & 5 & $2.40 \%$ \\
Type of delivery & $\mathbf{N}=\mathbf{2 0 9}$ & \\
Other & 3 & $1.40 \%$ \\
SVD & 195 & $93.30 \%$ \\
SVD + episiotomy & 8 & $3.80 \%$ \\
Episiotomy + assisted vacuum & 2 & $1.00 \%$ \\
Assisted vacuum only & 1 & $0.50 \%$ \\
Position assumed at delivery & $\mathbf{N}=\mathbf{2 0 9}$ & \\
Lateral (side lying) & 8 & $3.80 \%$ \\
Lithotomy & 201 & $96.20 \%$ \\
Infant birth weight (Kgs) & $3.0(2.7,3.4)$ & \\
Median (IQR) & & \\
Infant sex & $\mathrm{N}=209$ & \\
Female & 98 & $46.90 \%$ \\
Male & 111 & $53.10 \%$ \\
\hline
\end{tabular}

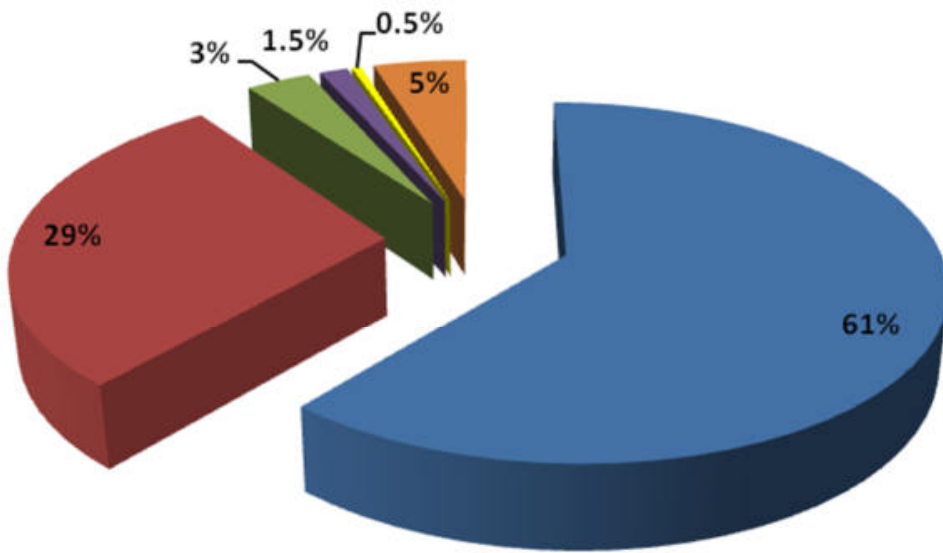

Intact

1st degree

2nd degree

3rd degree

4th degree

Episiotomy

Figure 2: Prevalence of perineal trauma

In the univariate analysis of risk factors for perineal trauma using a Chi-square, there was a statistical significance between age $(p=0.013)$, infant birth weight $(p=0.010)$, parity $(p=0.000)$ and history of previous trauma $(p=0.033)$, with perineal trauma (Table 3). 
Table 3: Univariate analysis of risk factors

\begin{tabular}{|c|c|c|c|}
\hline Variable & $\begin{array}{l}\text { No Trauma } \\
\mathrm{N}=128\end{array}$ & $\begin{array}{l}\text { Trauma } \\
\mathrm{N}=81\end{array}$ & Chi- square p-value \\
\hline & Freq (\%) & Freq $(\%)$ & \\
\hline \multicolumn{4}{|c|}{ Age in categories (yrs) } \\
\hline 20 & $13(50)$ & $13(50)$ & \\
\hline $20-24$ & $38(50)$ & $38(50)$ & \\
\hline $25-30$ & $44(73.3)$ & $16(26.7)$ & \\
\hline$>30$ & $33(70.21$ & $14(29.79)$ & 0.013 \\
\hline \multicolumn{4}{|c|}{ Infant birth weight (Kgs) } \\
\hline Median (IQR) & $3.0(2.7,3.2)$ & $3.1(2.9,3.4)$ & $0.010^{1}$ \\
\hline \multicolumn{4}{|l|}{ Parity } \\
\hline 0 & $41(42.3)$ & $56(57.7)$ & \\
\hline 1 & $38(70.4)$ & $16(29.6)$ & \\
\hline 2 & $19(79.2)$ & $5(20.8)$ & \\
\hline 3 or more & $30(88.2)$ & $4(11.8)$ & 0.000 \\
\hline \multicolumn{4}{|c|}{ Induction of labour } \\
\hline No & $118(60.5)$ & $77(39.5)$ & \\
\hline Yes & $10(71.4)$ & $4(28.6)$ & 0.418 \\
\hline \multicolumn{4}{|c|}{ Position assumed at delivery } \\
\hline \multicolumn{4}{|c|}{ Lateral (side lying) } \\
\hline \multirow[t]{2}{*}{ Lithotomy } & $6(75)$ & $2(25)$ & \\
\hline & $122(60.7)$ & $79(39.3)$ & 0.415 \\
\hline \multicolumn{4}{|c|}{ History of previous trauma } \\
\hline \multicolumn{4}{|c|}{ No } \\
\hline \multirow[t]{2}{*}{ Yes } & $89(57.1)$ & $67(42.9)$ & \\
\hline & $39(73.6)$ & $14(26.4)$ & 0.033 \\
\hline
\end{tabular}

Logistic regression was used to adjust for confounders. Adjusting for other factors, there was a statistically significant association between infant birth weight and perineal trauma $(\mathrm{p}=0.005) ; 95 \%$ CI $(1.369,6.051)$. The odds of sustaining perineal trauma increased with infant birth weight OR 2.878. Holding other factors constant, the odds of sustaining perineal trauma decreased with increasing parity. The odds ratio for a woman with para 3, sustaining perineal trauma was $0.037(95 \%$ CI $(0.008,0.180))$ times that of for a woman with para 0 (Table 4$)$.

Age, induction of labour, position and history of previous trauma were not statistically significant in the multivariate analysis.

Table 4: Multivariate analysis showing association between risk factors and perineal trauma

\begin{tabular}{llll}
\hline Variable & $\begin{array}{l}\text { Odds } \\
\text { Ratio }\end{array}$ & p-value & $95 \%$ CI \\
\hline $\begin{array}{l}\text { Age in categories (yrs) } \\
<20\end{array}$ & 1 & & \\
$20-24$ & 1.060 & 0.906 & $(0.407,2.756)$ \\
$25-30$ & 0.706 & 0.527 & $(0.240,2.078)$ \\
$>30$ & 1.722 & 0.440 & $(0.434,6.840)$ \\
& & & \\
Infant birth weight (Kgs) & 2.878 & 0.005 & $(1.369,6.051)$ \\
Parity & & & \\
0 & 1 & & $(0.096$, \\
1 & 0.239 & 0.002 & $(0.028,0.451)$ \\
2 & 0.112 & 0.002 & $(0.008,0.180)$ \\
3 & 0.037 & 0.000 & \\
Induction of labour & & & \\
Yes vs. No & & & $(0.158,2.437)$ \\
Position & & & \\
Lithotomy vs. Lateral & & & \\
History of previous trauma & 0.620 & 0.494 & $(0.526,15.764)$ \\
Yes vs. No & & & \\
\hline
\end{tabular}




\section{Discussion}

The study assessed the prevalence and risk factors for perineal trauma. The results of the study depicted a high prevalence of perineal trauma. The findings were consistent with findings of a similar study carried out by Oliveira et al., (2014). The findings were also similar with those by Melamed et al., (2013), where the prevalence of $3^{\text {rd }}$ and $4^{\text {th }}$ degree tears was $0.6 \%$ and $3^{\text {rd }}$ degree tears were more common than $4^{\text {th }}$ degree. In the multi-country study by Hirayama et al., (2012), the prevalence of severe perineal trauma in Kenya was slightly highly and the findings of the study, with the highest prevalence reported in the Philippines. The study revealed that mild perineal trauma was more common than severe trauma and this finding concurred with those of other similar studies.

The findings from this study indicated that there was an association between parity, maternal age, infant birth weight, and history of previous trauma with occurrence of perineal trauma. There was a higher likelihood of sustaining perineal trauma with increasing infant birth weight, but the possibility of sustaining trauma decreased with increasing parity. In a similar cross-sectional study by Oliviera et al., (2014), there was an association between primiparity and perineal trauma. Similarly, a retrospective case-control study found that there was an association between birth weight and perineal trauma where infant birth weight greater than 3.5 kilograms was found to be predictive of $3^{\text {rd }}$ and $4^{\text {th }}$ degree tears (Lewis et al., 2011). In this study, episiotomy was not routinely performed. This finding was consistent to a study by Gurol-Urganci et al., (2013), which depicted a decrease in the rates of episiotomy between the year 2000 and 2012.

In this study, adjusting for other factors, the odds of sustaining perineal trauma increased with infant birth weight and decreased with increasing parity. This was consistent with study findings by Hirayama et al., (2011), where nulliparity and high infant birth weight significantly increased the risk of third and fourth degree perineal tears in Africa, Asia and Latin America. However, study findings by Gurol-Urganci et al., (2013), found that the adjusted risk of severe trauma increased with birth weight and increased maternal age. In contrast to this study, maternal age was not statistically significant in its association with trauma, in the logistic regression.

The study revealed that induction of labour was not statistically significant, associated with perineal trauma. The odds of sustaining trauma when labour was induced was OR $0.620 ; 95 \%$ CI $(0.158,2.437)$. In a multi-country study, odds ratio for induction of labour was OR 1.53, 1.38, 1.38, in Africa, Asia and Latin America respectively (Hirayama et al., 2011). These findings were in tandem with those of this study where induction of labour was not found to increase the risk of perineal trauma.

This study revealed that position assumed during delivery, lithotomy versus lateral, was not statistically significant, associated with perineal trauma. This finding was in contrast to that of Daniidilis et al., (2012), where delivery with stirrups in lithotomy position was one of the risk factors for third degree perineal tears. History of previous trauma was statistically significant in its association with perineal trauma. These findings were similar to a study by Yogev et al., (2014), where women who had experienced $3^{\text {rd }}$ or $4^{\text {th }}$ degree perineal tears in previous deliveries, were at a 5-fold risk of these types of tears in subsequent pregnancies.

\section{Conclusion}

The prevalence of perineal trauma was found to be $38.8 \%$, with mild trauma being very common as compared to $3^{\text {rd }}$ and $4^{\text {th }}$ degree tears. Perineal tears were more common than episiotomy, even in women who had delivered previously. A previous delivery or deliveries did not determine whether a woman would sustain a tear or not. Parity, maternal age, infant birth weight and history of previous trauma were found to be associated with perineal trauma in this study, though many studies had found that nulliparity and infant birth weight were the main factors associated with trauma. This study confirmed what other studies had previously found, that vaginal delivery was associated with a high incidence of perineal trauma.

\section{Recommendations}

The study recommends evidence based approaches for the management of second stage of labour in order to improve maternal pelvic floor outcomes as well as reduce caesarean sections, operative deliveries and long term complications. The study also recommends multi-facility studies on prevalence of perineal trauma in Kenya.

\section{Acknowledgement}

We wish to convey our gratitude to all those who gave their time to participate in this study.

\section{Conflict of interest}

The authors declare that they have no conflict of interest.

\section{References}

Dahlen, H., Priddis, H. Schmeid, V., Sneddon, A., Kettle, C., Brown, C., \& Thornton, C. (2013). Trends and factors 
for severe perineal trauma during childbirth in New South Wales between 2000 and 2008: a population-based data study. BMJ Open, 3 :e002824. Doi: 10.1136/bmjopen-21013-002824 accessed on 25/07/2014

Daniilidis, A., Markis, V., Tzafetas, M., Loufopoulos, P., Hatzis, P., Vrachnis N., \& Dinas K. (2012). Third degree lacerations- How, Why and When? A Review Analysis. Open Journal of Obstetrics and Gynecology, 2: 304-310 http://dx.doi.org/10.4236/ojog.2012.23064.

Gabbe, S. G., Niebyl, J. R. \& Simpson, J. L. (2007). Obstetrics: Normal and Problem Pregnancies, (5 ${ }^{\text {th }}$ Ed). Philadelphia: Churchill Livingstone;

Gurol-Urganci, I., Cromwell, D., Edozien, L., Mahmood, T., Adams, E., Richmond, D., Templeton, A., \& van der Meulen, J. H. (2013). Third- and fourth-degree perineal tears among primiparous women in England between 2000 and 2012: time trends and risk factors. BJOG, 120: 1516-1525

Hirayama, F., Koyanagi, A., Mori, R., Zhang, J., Souza, J., \& Gu“lmezoglu, A. (2012). Prevalence and risk factors for third- and fourth-degree perineal lacerations during vaginal delivery: a multi-country study. BJOG, 119:340 347 doi:10.1111/1471-0528.12363

Jackson, K. B. (2000). The bottom line: Care of the perineum must be improved. British Journal of Midwifery 05 Oct, 8 (10) 05: 609-614.

Komorowski, L., Leeman, L. M., Fullilove, M. A., Bedrick, E. J., Migliacio, D. L., \& Rogers, R. G. (2014). Does a Large Infant Head or a Short Perineal Body Increase the Risk of Obstetrical Perineal Trauma? Birth June, 2: $147-152$

Kudish, B., Sokol, R. J., \& Kruger, M. (2008). Trends in major modifiable risk factors for severe perineal trauma, 1996-2006. International Journal of Gynecology and Obstetrics, 102: 165-170

Lemos, A., Amorim, M. M. R., Dornelas de Andrade, A., de Souza, A. L., Cabral Filho, J. E. \& Correia, J. B. (2011). Pushing/ bearing down methods for the second stage of labour. Cochrane Database of Systematic Reviews, 5: CD009124. DOI: 10.1002/14651858.CD009124.

Lewis, T., Da Costa, V., Harriot, J., Wynter, S., Christie, S., \& Cawich, S. (2011). Factors Related to Obstetric Third and Fourth Degree Perineal Lacerations in a Jamaican Cohort. West Indian Med J, 60(2): 195-198

Melamed, N., Gavish, O., Eisner, M., Wiznitzer, A., Wasserberg, N., \& Yogev, Y. (2013). Third- and fourth-degree tears- incidence and risk factors. The Journal of Maternal-fetal \& Neonatal Medicine, 26 (7): 660-664

Meyvis, I., Van Rompaey, B., Goormans, K., Truijen, S., Lambers, S., Mestdagh, E., \& Mistiaen, W. (2012). Maternal Positions and Other Variables. Birth June, 39: (2) 115-120

Oliveira, L. S., Brito, L. G. O., Quintana, S. M., Duarte, G., \& Marcolin, A. C. (2014). Perineal trauma after vaginal delivery in healthy pregnant women. Sao Paulo Med J., 132 (4): 231-238 DOI:10.1590/1516-3180.2014.1324710

Romano, A. M., \& Lothian, J. A. (2008). Promoting, Protecting and Supporting Normal Birth: A Look at the Evidence. JOGNN, 37 (1): 94- 105. Doi: 10.1111/J.1552-6909.2007.00210.x

Yogev, Y., Hiersch, L., Maresky, L., Wasserberg, N., Wiznitzer, A., \& Melamed, N. (2014). Third and Fourth degree perineal tears- the risk of recurrence in subsequent pregnancy. The Journal of Maternal-Fetal \& Neonatal Medicine, 27(2): 177-181 